\title{
Dissimilar Associates of Dyes in Aqueous Solutions: Experimental Study and Computer Simulation ${ }^{1}$
}

\author{
Sergey A. Shapovalov \\ Research Institute of Chemistry, V N. Karazin Kharkiv National University, \\ Svobody Sq., 4, Kharkiv 61022, Ukraine \\ serghey.a.shapovalov@karazin.ua
}

Keywords: dissimilar associates, dyes, simulation, solutions, enthalpy of formation, spectroscopy. Dissimilar cation-anionic association of dyes («cyanine+oxyxanthene», «cyanine+sulfonepthalein») has been regularly investigated in aqueous solutions. Experimental (by spectrophotometry) and theoretical (by semiempirical) methods were used. The basic regularities of association processes have been discussed. It is shown that the change in the stability of associates has a systematic character both in the series of singly charged and doubly charged anions. The experimentally determined values (of equilibrium constant of association) and simulated values (of standard enthalpy of hydration of associates) are mutually consistent. The standard enthalpy of formation and the most probable structures of associates have been determined.

1 The manuscript is based on the report: Shapovalov S. A. «Association of Dyes in Aqueous Solutions: Experimental Study and Computer Simulation», IX International Conference in Chemistry KyivToulouse (ICKT-9), 4-9 June 2017, Kyiv, Ukraine. 


\section{Introduction}

The processes of association of dye molecules have a significant effect on the light absorption and luminescence of aqueous solutions [1-4]. The formation of dimers and more associated structures (self-associates) is recorded at concentrations of $5 \cdot 10^{-5} \mathrm{~mol} / \mathrm{L}$ and higher [5-11]. The cation-anion association, as a kind of association between dyes of different structures, leads to the formation of fairly stable stoichiometric compounds at concentrations of polyatomic particles of $1 \cdot 10^{-6}-1 \cdot 10^{-5} \mathrm{~mol} / \mathrm{L}$. Such association is characterized by a variety of spectral effects, including the appearance of absorption bands or their shifts. In practical terms, the association is considered as an effective factor for changing the spectralluminescent characteristics of solutions.

Extending the notion of the association of polyatomic particles is important for the development of scientific fields, such as chemical analysis, analytical chemistry of pharmaceuticals, surface chemistry, cell and DNA biochemistry [12-20]. For this reason, the study of regularities of cation-anionic dye association is relevant, as well as determination of the influence of several factors (first of all, the structure and charge of the ions) on the stability of associates.

Electronic spectroscopy, theoretical methods and computer simulation have been used successfully for the study of complex supramolecular systems. They allow one to study and interpret the formation of associates at particle concentrations of not more than $1 \cdot 10^{-5} \mathrm{~mol} / \mathrm{L}$ [21-25].

In this paper, the equilibrium properties of cation-anion associates are considered, their most probable structures are discussed, and the agreement between the experimental data and computer simulation is analyzed. Associates had in their composition cations of cyanine dyes and anions of sulfonephthaleins and oxyxanthenes.

\section{Experimental part}

Materials

Pinacyanol chloride (PNC)

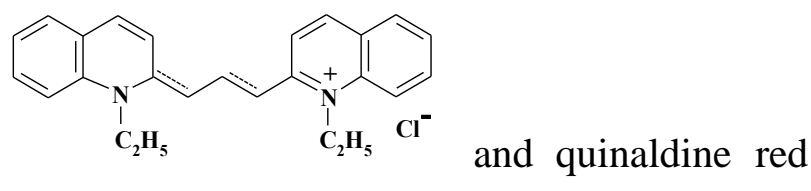

$(\mathrm{QR})$

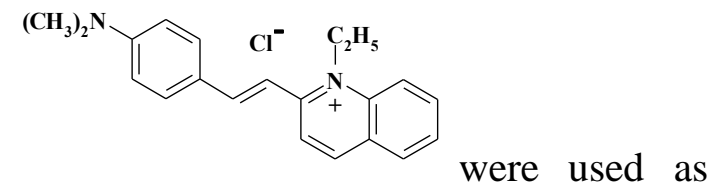

the cationic cyanine dyes $\left(\mathrm{Ct}^{+}\right)$.

The well-known phenol red (PR), cresol red (CR), thymol blue (TB), bromothymol blue (BTB), bromocresol purple (BCP), bromocresol green $(\mathrm{BCG})$, bromophenol blue (BPB) were used as anionic sulfonephthaleins. The wellknown fluorescein (FL), eosin (EO), ethyleosin (EE), tetrabromophenylfluoron (TBPF), erythrosine (ER), Bengal Rose B (BRB) have been investigated as oxyxanthene anions. The preparations of the dyes were of the "Sigma" trade mark with the $95 \%$ contents of the main substance. The chemical purity of the dyes was checked spectrophotometrically using known values of the molar extinction coefficient. 


\section{Methods}

The intrinsic absorption of individual forms of dyes was taken into account when determining the spectrophotometric characteristics of dissimilar associates.

Using previously obtained data on the composition of the associates [25], the cationanionic interactions of the dyes were considered in accordance with such equilibria:

$$
\mathrm{Ct}^{+}+\mathrm{HAn}^{-} \rightleftarrows \mathrm{Ct}^{+} \cdot \mathrm{HAn}^{-}
$$

and

$$
2 \mathrm{Ct}^{+}+\mathrm{An}^{2-} \rightleftarrows\left(\mathrm{Ct}^{+}\right)_{2} \cdot \mathrm{An}^{2-} .
$$

Equilibrium constants of association $\left(K_{\text {as }}\right)$ were calculated according to the law of acting masses respectively:

$$
K_{a s}=\frac{\left[\mathrm{Ct}^{+} \cdot \mathrm{HAn}^{-}\right]}{\left(C_{\mathrm{HAn}^{-}}-\left[\mathrm{Ct}^{+} \cdot \mathrm{HAn}^{-}\right]\right) \times\left(C_{\mathrm{Ct}^{+}}-\left[\mathrm{Ct}^{+} \cdot \mathrm{HAn}^{-}\right]\right)}
$$

and

$$
K_{a s}=\frac{\left[\left(\mathrm{Ct}^{+}\right)_{2} \cdot \mathrm{An}^{2-}\right]}{\left(C_{\mathrm{An}^{2-}}-\left[\left(\mathrm{Ct}^{+}\right)_{2} \cdot \mathrm{An}^{2-}\right]\right) \times\left(C_{\mathrm{Ct}^{+}}-2\left[\left(\mathrm{Ct}^{+}\right)_{2} \cdot \mathrm{An}^{2-}\right]\right)^{2}}
$$

where the equilibrium concentrations of the associates are:

$$
\left[\mathrm{Ct}^{+} \cdot \mathrm{HAn}^{-}\right]=\frac{\varepsilon_{\mathrm{Ct}^{+}} \times C_{\mathrm{Ct}^{+}} \times l-A}{\left(\varepsilon_{\mathrm{Ct}^{+}}-\varepsilon_{\mathrm{as}}\right) \times l}
$$

and

$$
\left[\left(\mathrm{Ct}^{+}\right)_{2} \cdot \mathrm{An}^{2-}\right]=\frac{\varepsilon_{\mathrm{Ct}^{+}} \times C_{\mathrm{Ct}^{+}} \times l-A}{\left(2 \varepsilon_{\mathrm{Ct}^{+}}-\varepsilon_{\mathrm{as}}\right) \times l} .
$$

Notation: $C$ is the initial molar concentrations of the cation or anion; $l$ is the absorbing layer thickness; $A$ is the optical density of the solution at the fixed wavelength; and $\varepsilon$ is the molar extinction coefficient of the cation or the associate. The numerical $A$ values which form the basis for calculating the $K_{\text {as }}$ were checked for compliance with the basic law of light absorption.

For the calculation of the association constants, the equilibrium concentrations of the associate were determined from the spectral data in the region of $v_{\max }$ of cation. The search for $\left[\mathrm{Ct}^{+} \cdot \mathrm{HAn}^{-}\right]$or $\left[\left(\mathrm{Ct}^{+}\right)_{2} \cdot \mathrm{An}^{2-}\right]$ values is substantially facilitated by the fact that the association is pronounced. And it is not necessary to create of large excesses of the $\mathrm{HAn}^{-}$or $\mathrm{An}^{2-}$ concentrations. The intrinsic light absorption of anionic dyes in the absorption region of the cation is very small due to the use of low initial concentrations of anions and a significant difference in the $v_{\max }$ values between cation and anion (for example, $v_{\max }=$ $16670 \mathrm{~cm}^{-1}$ for $\mathrm{Ct}^{+}$of PNC [23] and $v_{\max }=$ $16670 \mathrm{~cm}^{-1}$ for $\mathrm{HAn}^{-}$of PR [25]). So, the formulas do not take into account the absorption of $\mathrm{HAn}^{-}$or $\mathrm{An}^{2-}$ because their contribution in was not substantial under analysis.

Very dilute solutions of dyes were used and the ionic strength (I) of photometric solutions did not exceed 0.001-0.008 mol/L. So, the concentration association constant is actually thermodynamic at such values of $I$. The details of the measurement procedure are set out earlier [25].

Software applications "HyperChem 8.0", "MOPAC 2012", (evaluation or license versions) were used to determine the 
characteristics of associates. To estimate the values of the standard enthalpy of hydration, $\Delta H^{\circ}$, the AM 1 semiempirical method was used. Method AM 1 is one of the extended variants of the MNDO method. This method has been parametrized in such a way that the experimental values of $\Delta H_{\mathrm{f}}^{\circ}$ of organic compounds would be reproduced most adequately The average inaccuracy of the AM 1 method in the calculation of $\Delta H^{\circ}{ }_{\mathrm{f}}$ is $25 \mathrm{~kJ} / \mathrm{mol}$. Note that similar nonempirical simulations give inaccuracies of the values of $\Delta H_{\mathrm{f}}^{\circ}$ exceeding $100 \mathrm{~kJ} / \mathrm{mol}$ even for small molecules. With an increase in the number of atoms in the molecule, the inaccuracies in the calculated values of $\Delta H^{\circ}{ }_{f}$ increase more and gain a systematic character [26-28]. The MOPAC procedure essentially accelerates the calculations by using the AM 1 method, and the application "HyperChem 8.0" makes it possible to visualize the structure of ions and associates.

\section{Results and discussion}

\section{Experimental study of dyes association}

A significant decrease in the intensity of light absorption is a characteristic feature of a dissimilar association. This decrease is clearly seen as the addition of increasing amounts of one dye to the unchanged content of the other. The most typical cases are presented in Figure 1 (decrease in the absorption intensity) and Figure 2 (shifts of the absorption band and the appearance of a new band).

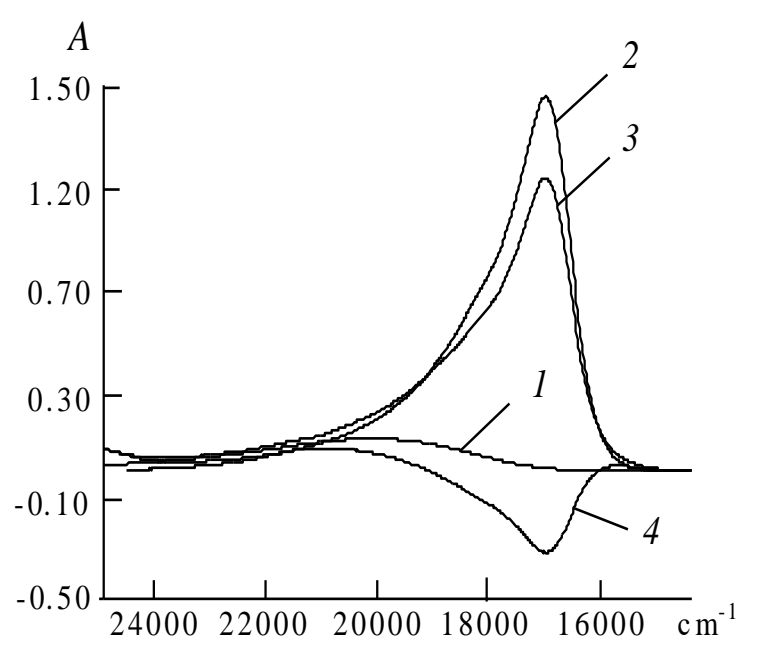

Figure 1. Light absorption of aqueous solutions containing QR and BTB. Concentrations, mol/L, of QR: $1,3-2 \cdot 10^{-5}, 2-0$; of BTB: $1-0,2,3-4 \cdot 10^{-5}, 4-$ is nonadditivity curve. The reference solution is water. The absorbing layer thickness is $0.2 \mathrm{~cm}$. pH 7.0.

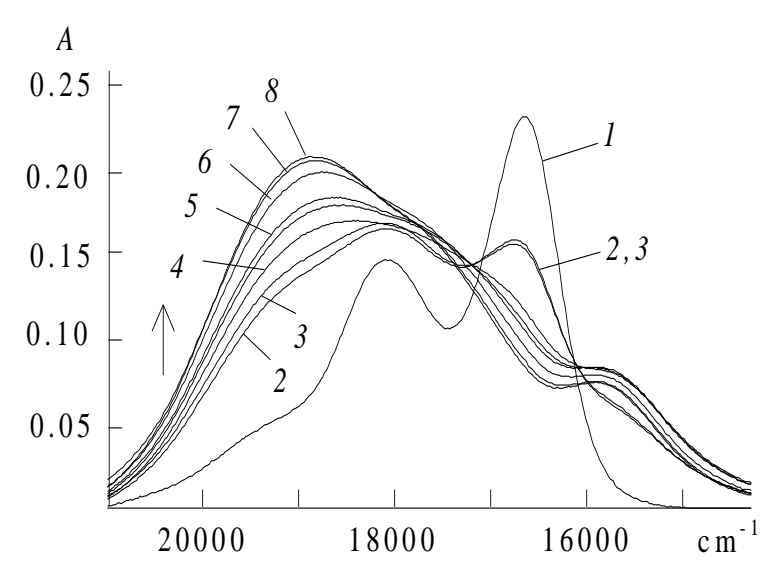

Figure 2. Light absorption of aqueous solutions containing PNC and BTB. Concentrations, mol/L, of PNC: $1-8-4.9 \cdot 10^{-6}$, of BTB: $1-0,2-4 \cdot 10^{-6}, 3-$ $4.5 \cdot 10^{-6}, 4-5 \cdot 10^{-6}, 5-1 \cdot 10^{-5}, 6-1.25 \cdot 10^{-5}, 7-1.5 \cdot 10^{-5}, 8$ $-2 \cdot 10^{-5}$. The reference solution is water. The absorbing layer thickness is $1.0 \mathrm{~cm} . \mathrm{pH} 3.6$.

Analysis of the absorption spectra reveals the nonadditivity of the spectral bands. It consists in that the intensity of $A$ values of a mixture of counterions is systematically less than the total light absorption of individual ions 
(curve 4 in Figure 1). Areas with a negative value of $A$ indicate a tangible interaction of counterions and the formation of ionic associates. A similar situation is observed in the association of rhodamines or indopolycarbocyanines [25].

According to the spectrophotometric data and the above formulas, the $K_{\text {as }}$ values were calculated for dissimilar associates of PNC (Table 1). EE and TBPF do not form doubly charged anions. The solutions containing singly charged cations of dyes in strongly acidic and basic media are considerably decolorized in consequence of the processes $\mathrm{Ct}^{+}+\mathrm{H}^{+} \rightarrow \mathrm{HCt}^{2+}$ and $\mathrm{Ct}^{+}+\mathrm{OH}^{-} \rightarrow \mathrm{CtOH}$ correspondingly due to the disturbance of the conjugation of the polymethine chain of the chromophore. Therefore, the fact of the interaction of singlecharged BCG and BPB anions, as well as the double-charged anion of a TB with a cation $\mathrm{Ct}^{+}$ of PNC is not experimentally determined. In addition, the existence of these sulfonephthalein anions is possible at $\mathrm{pH}$ values that do not coincide with the area of existence of the PNC cation.

Table 1. Values of $\log K_{\text {as }}$ for PNC associates

\begin{tabular}{|c|c|c|}
\hline \multirow{2}{*}{ Dye } & \multicolumn{2}{|c|}{$\log K_{\text {as }}$} \\
\cline { 2 - 3 } & $\mathrm{Ct}^{+} \cdot \mathrm{HA}^{-}$ & $\left(\mathrm{Ct}^{+}\right)_{2} \cdot \mathrm{An}^{2-}$ \\
\hline PR & $5.83 \pm 0.10$ & $11.81 \pm 0.10$ \\
\hline CR & $4.59 \pm 0.03$ & $10.96 \pm 0.10$ \\
\hline TB & $5.29 \pm 0.05$ & \\
\hline BTB & $5.95 \pm 0.11$ & $10.89 \pm 0.09$ \\
\hline BCP & $6.67 \pm 0.04$ & $11.07 \pm 0.10$ \\
\hline BCG & & $12.09 \pm 0.09$ \\
\hline BPB & & $13.73 \pm 0.10$ \\
\hline
\end{tabular}

\begin{tabular}{|c|c|c|}
\hline FL & $4.58 \pm 0.11$ & $9.75 \pm 0.10$ \\
\hline EE & $5.45 \pm 0.09$ & - \\
\hline TBPF & $6.38 \pm 0.11$ & - \\
\hline EO & & $11.25 \pm 0.10$ \\
\hline ER & & $11.84 \pm 0.10$ \\
\hline BRB & & $13.46 \pm 0.11$ \\
\hline
\end{tabular}

The study of the interaction of PNC with singly-charged anions of EO, ER, BRB is also difficult. Due to the proximity of the values of $\mathrm{p} K_{\mathrm{a} 1}$ and $\mathrm{p} K_{\mathrm{a} 2}$ of these oxyxanthenes, no $100 \%$ yield of the singly charged anion can be obtained at any $\mathrm{pH}$ value. Therefore, associates of the $\mathrm{Ct}^{+} \cdot \mathrm{HA}^{-}$composition of these oxyxanthenes have not been studied.

The data of the table indicate a statistically significant difference in the values of $K_{\text {as }}$ for associates of the same stoichiometric composition. In all cases, the $K_{\text {as }}$ values are comparable with the known values of the equilibrium complexation constants [10, 11], when, unlike the association process, new valence bonds arise between the reacting particles.

\section{Computer simulation of dyes association}

The obtained experimental results allow us to conclude that alkyl substituents in the sulfonephthalein or oxyxanthene structures contribute to a decrease of $K_{\text {as }}$ values, while the halogen atoms, in contrast, increase of $K_{\text {as }}$ values. To explain the course of the $K_{\text {as }}$ change, a number of design characteristics have been tested, among them the effective area of the molecule, its volume, the hydrophobicity index. However, the standard enthalpy of hydration 
$\Delta H^{\circ}$ hydr reflects the state of the ion in the solution to the greatest extent. Let's consider it on an example of PNC associates.

The values of $\Delta H^{\circ}$ hydr $(\mathrm{kJ} / \mathrm{mol}$, in brackets) are located for the anions of sulfonephthaleins in the following sequence:

$\mathrm{HAn}^{-}:$CR $(-45.4)<$ TB $(-29.8)<$ BTB $(-27.4)<$ BCP (-26.0),

$\mathrm{An}^{2-}:$ BTB $(-25.6) \approx \mathrm{CR}(-24.4)<\mathrm{BCP}(-9.7)<$ BCG (-2.5) < BPB (-1.3).

The changes in the $\Delta H^{\circ}{ }_{\text {hydr }}$ of oxyxanthene anions are:

HAn $^{-}:$FL $(-60.9)<$ EE $(-2.3)<\operatorname{TBPF}(-0.8)$,

$\mathrm{An}^{2-}:$ FL $(-45.3)<\mathrm{EO}(+1.0)<\mathrm{ER}(+7.4)<$ $\mathrm{BRB}(+26.6)$.

For anions of sulfonephthaleins, an increase in the stability of associates is in agreement with an increase in the $\Delta H^{\circ}$ hydr anions ( $\log K_{\text {as }}$ values are set in brackets):

$$
\begin{gathered}
\mathrm{HAn}^{-}: \mathrm{CR}(4.59)<\mathrm{TB}(5.29)<\mathrm{BTB}(5.95)< \\
\mathrm{BCP}(6.67), \\
\mathrm{An}^{2-}: \mathrm{BTB}(10.89)<\mathrm{CR}(10.96) \approx \mathrm{BCP}(11.07) \\
<\mathrm{BCG}(12.09)<\mathrm{BPB}(13.73) .
\end{gathered}
$$

Associates of oxyxanthene anions are arranged in stability in the following sequence:

$$
\begin{gathered}
\mathrm{HAn}^{-}: \mathrm{FL}(4.58)<\mathrm{EE}(5.45)<\mathrm{TBPF}(6.38), \\
\mathrm{An}^{2-}: \mathrm{FL}(9.75)<\mathrm{EO}(11.25)<\mathrm{ER}(+11.84)< \\
\mathrm{BRB}(+13.46) .
\end{gathered}
$$

These sequences also correlate well with the corresponding of the increase in the $\Delta H^{\circ}$ hydr values. Thus, the satisfactory agreement between the experimentally $K_{\text {as }}$ values with theoretically determined of $\Delta H^{\circ}$ hydr values is observed for sulfonephthaleins or oxyxanthenes dissimilar associates.

Note that the association is inherent in dyes, which have a planar form of the molecule. Hydrophobicity, the presence of developed $\pi$ conjugated electron fragments significantly enhance dispersion interactions and also promote association. However, the investigated anionic dyes are not flat $\pi$-electronic systems, in contrast to cations of cyanines. However, as follows from the experimental data, a significant interaction occurs between $\mathrm{Ct}^{+}$and anions. It can be assumed that the planar cation is coordinated by a singly charged anion or two cations by a single doubly charged anion. The most probable structures of stoichiometric associates were defined and the values of the standard enthalpy of formation of associates were determined.

Finding a global energy minimum is necessary for the correct determination of the $\Delta H^{\circ}$ f. For this, 6-7 different starting mutual positions of counterions in the associate were tested. Each of the counterions was geometrically optimized previously. From the set of energy (so-called local) minima, the smallest has been chosen. The energy of this structure was assumed to correspond to the global energy minimum. As an example, Figure 3 shows the dynamics of $\Delta H^{\circ}$ changes depending on the values of the RMS-gradient for the associates of $\mathrm{QR}$ with $\mathrm{BCG}$. 


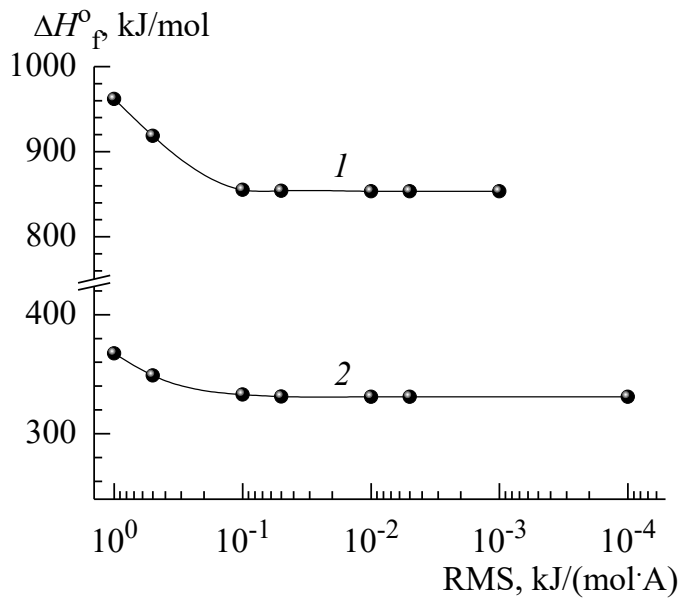

Figure 3. The change in $\Delta H_{\mathrm{f}}^{\circ}$ as a function of RMSgradient values. $1-\left(\mathrm{QR}^{+}\right)_{2} \cdot \mathrm{BCG}^{2-}$ associate; $2-$ $\mathrm{QR}^{+} \cdot \mathrm{BCG}^{-}$associate.

Note, that the RMS-gradient, $\mathrm{kJ} /(\mathrm{mol} \cdot \AA)$, is the rate of change of energy with a change in the arrangement of each atom in three mutually perpendicular directions.

The optimized arrangement ions in the associate $\left(\mathrm{QR}^{+}\right)_{2} \cdot \mathrm{BCG}^{2-}$ is presented in Figure 4 (stereo-image, hydrogen atoms are not shown).
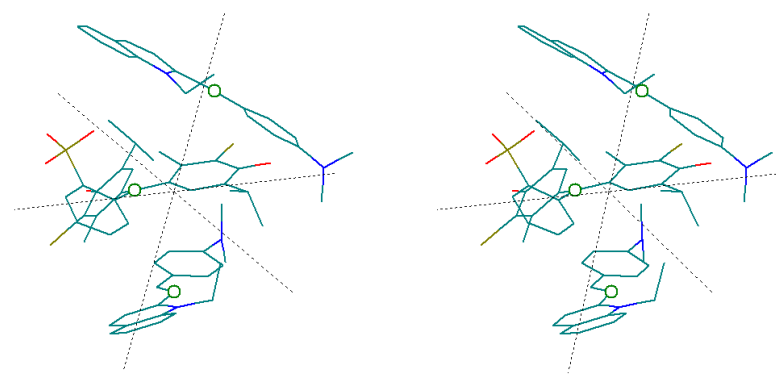

Figure 4. The arrangement of ions in the $\left(\mathrm{QR}^{+}\right)_{2} \cdot \mathrm{BTB}^{2-}$ associate $\left(\mathrm{BTB}^{2-}\right.$ is at the center; the distance between the isolated middle atom and the upper one is $6.7 \AA$, the mean and the lower is $4.6 \AA$, the central angle is $97^{\circ}$ ).

The progress of structural optimization depends significantly on RMS values, but is practically finalized already at $0.01 \mathrm{~kJ} / \mathrm{mol}$ and is accompanied by a decrease in the distance between counterions.

The energy diagrams of dyes and an $\left(\mathrm{Ct}^{+}\right)_{2} \cdot \mathrm{An}^{2-}$ associate between $\mathrm{QR}$ and $\mathrm{BPB}$ are shown as an example in Figure 5 (the numbers at the arrows denote the range of variation of the values of $\Delta H_{\mathrm{f}}^{\circ}$ ).

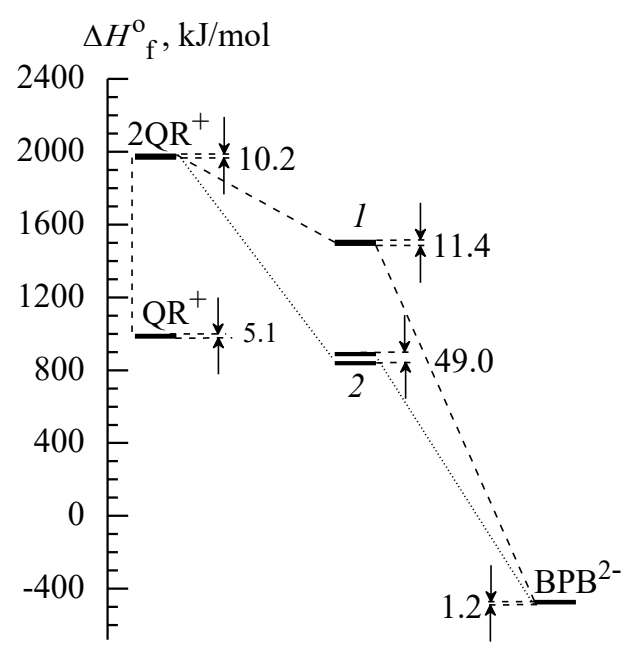

Figure 5. The $\Delta H_{\mathrm{f}}^{\circ}$ values of the $\mathrm{QR}^{+}, \mathrm{BPB}^{2-}$ ions and associate. 1 - The algebraic sum of the counters ions; $2-$ $\Delta H^{\circ}$ of the associate.

The excess of the algebraic sum of the $\Delta H^{\circ}$ f values of counterions $(1494 \mathrm{~kJ} / \mathrm{mol}$, level 1) with respect to $\Delta H_{\mathrm{f}}^{\circ}$ of associate $(839 \mathrm{~kJ} / \mathrm{mol}$, level 2) is $655 \mathrm{~kJ} / \mathrm{mol}$. This excess of the $\Delta H_{\mathrm{f}}^{\circ}$ value is significantly higher than the average error (is about $25 \mathrm{~kJ} / \mathrm{mol}$ ) of the simulation AM1 method [26, 27].

Calculations also show that the similar excesses of the $\Delta H^{\circ}$ value are higher for associates of PNC cation. Thus, $\Delta H^{\circ}$ excess is $649 \mathrm{~kJ} / \mathrm{mol}$ for "PNC $+\mathrm{BTB}^{2--"}$ associate, but $\Delta H^{\circ}{ }_{\mathrm{f}}$ excess is only $605 \mathrm{~kJ} / \mathrm{mol}$ for " $\mathrm{QB}^{+}+$ $\mathrm{BTB}^{2-»}$ associate. Since the error of $\Delta H_{\mathrm{f}}^{\circ}$ is no higher than the mentioned average error of the 
method, we can state that the formation of all associates is energetically advantageous, especially in the association of dyes with structures containing developed $\pi$-electron systems, where the advantage is $\sim 150$ $160 \mathrm{~kJ} / \mathrm{mol}$ (for $\mathrm{Ct}^{+} \cdot \mathrm{HA}^{-}$associates) and $605-$ $700 \mathrm{~kJ} / \mathrm{mol}$ (for $\left(\mathrm{Ct}^{+}\right)_{2} \cdot \mathrm{An}^{2-}$ associates).

\section{Conclusions}

Unobvious experimental and theoretical results have been obtained in the study of the formation of dissimilar associates of dyes in aqueous solutions. Association of polyatomic particles was interpreted as part of an equilibrium model of intermolecular interactions. The satisfactory agreement between the experimentally $K_{\text {as }}$ values with theoretically determined of $\Delta H^{\circ}$ hydr values has been revealed. The combination of instrumental and theoretical methods made it possible to establish spectral and equilibrium regularities of the cation-anionic association of dyes, as well as to get the $\Delta H_{\mathrm{f}}^{\circ}$ values and a design of the most probable structure of associates.

\section{References}

[1] Ishchenko AA, Shapovalov SA. Heterogeneous association of the ions of dyes in solutions (review). J. Appl. Spectr. (Belarus). 2004; 71(5): 605-629.

[2] Yamaguchi A, Kometani N, Yonezawa Y. Luminescence properties of the mixed $\mathrm{J}$-aggregate of oxacyanine dye and thiacyanine dye. Formation of a persistence-type aggregate. J. Phys. Chem. B. 2005; 109(4): 1408-1414.
[3] Shapiro BI. Molecular assemblies of polymethine dyes. Russ. Chem. Rev. 2006; 75(5): 433456.

[4] Kaliteevskaya EN, Krutyakova VP, Razumova TK, Starovoitov AA. The influence of the molecular structure of cyanine dye on the component composition of molecular layers. Opt. Spectrosc. 2016; 120(3): 482-491.

[5] Arslanov VV. Polymer monolayers and Langmuir-Blodgett films. Polythiophenes. Russ. Chem. Rev. 2000; 69(10): 883-898.

[6] Murakami K. Thermodynamic and kinetic aspects of self-association of dyes in aqueous solution. Dyes and Pigments. 2002; 53(1): 31-43.

[7] Hoeben FJM, Jonkheijm P, Meijer EW, Schenning APH. About supramolecular assemblies of $\pi$ conjugated systems. J. Chem. Rev. 2005; 105(4): 14911546.

[8] Chen Z, Lohr A, Saha-Möller CR, Würthner F. Self-assembled $\pi$-stacks of functional dyes in solution: structural and thermodynamic features. Chem. Soc. Rev. 2009; 38(2): 564-584.

[9] Setiawan D, Kazaryan A, Martoprawiro MA, Filatov M. A first principles study of fluorescence quenching in rhodamine B dimers: how can quenching occur in dimeric species? Phys. Chem. Chem. Phys. 2010; 12(37): 11238-11244.

[10] Rehm TH, Schmuck C. Ion-pair induced self-assembly in aqueous solvents. Chem. Soc. Rev. 2010; 39(10): 3597-3611.

[11] Shapovalov SA. The association processes of protolytic forms of dyes in solutions. Self-association. Kharkiv: Brovin Publishing House; 2012, 218 P.

[12] Pronkin PG, Tatikolov AS. Study of cistrans equilibrium of oxacarbocyanine dyes in solution and 
in a complex with DNA. High Energy Chemistry (Rus.). 2012; 46(4): 253-258.

[13] Shahid M, Shahid-ul-Islam, Mohammad F. Recent advancements in natural dye applications: a review. J. Cleaner Production. 2013; 53: 310-331.

[14] Hu L, Yuan H, Li QQ, Jin JC, Chang WG, Yan ZQ. Spectral properties of a water-soluble squaraine dye and its application in cell fluorescent imaging. J. Appl. Spectr. (Belarus). 2015; 82(4): 665-668.

[15] Maskevich AA, Lavysh AV, Kuznetsova IM, Sulatskaya AI, Turoverov KK. Spectral manifestations of thioflavin $\mathrm{T}$ aggregation. J. Appl. Spectr. (Belarus). 2015; 82(1): 33-39.

[16] Tarasevich YI, Tryfonova MY. Adsorption of organic anions and cations from aqueous solutions on organosubstituted layered silicates. Chemistry, Physics and Technology of Surface (Ukr.). 2015; 6(1): 56-66.

[17] Malyukin YV, Yefimova SL, Tkacheva TN, Grygorova GV. Ordered adsorption of organic molecules on inorganic nanoparticles. Bulletin of the National Academy of Sciences of Ukraine (Ukr.). 2015; 6: 34-42.

[18] Tkachenko SV, Chernikova EY, Minkovska S, Deligeorgiev T, Fedorova OA, Fedorov YV. Multicomponent molecular ensembles of bysstyryl dye with cucurbit[7]uril: structure and spectral characteristics. Successes in Chemistry and Chemical Technology (Rus.). 2015; 29(7): 117-120.

[19] Baranovsky SF, Buchelnikov AS, Chernyshev DN, Astafieva DA. Study of the association of biologically active heterogeneous molecules. Topical Issues of Biological Physics and Chemistry (Russ.). 2016; 1(1): 164-169.

[20] Pronkin PG, Tatikolov AS. The study of the formation of J-aggregates of the anionic oxacarbocyanine dye upon interaction with proteins and polyelectrolytes. J. Appl. Spectr. (Belarus). 2017; 84(2): 192-200.
[21] Shestopalova AV. The investigation of the association of caffeine and actinocin derivatives in aqueous solution: A molecular dynamics simulation. J. Molec. Liquids. 2006; 127(1-3): 113-117.

[22] Ovchinnikov DV, Baranovsky SF, Rozvadovska AO, Rogova OV, Veselkov KA, Ermolaev DV, Parkes H, Davies DB, Evstigneev MP. Structural basis for the binding affinity of a homologous series of synthetic phenoxazone drugs with DNA: NMR and molecular mechanics analysis. J. Biomol. Struct. Dyn. 2007; 24(5): 443-453.

[23] Shapovalov SA, Samoilov EA. Regularities of homo- and heteroassociation of the pinacyanol cation in aqueous solution. Russ. Chem. Bull. (Internat. Ed.). 2008; 57(7): 1405-1415.

[24] Lipatova IM, Mezina EA, Yusova AA. Spectrophotometric research of chitosan complexing with phthalocyanine dyes. Proceedings of the Ufa Scientific Center of the Russian Academy of Sciences (Rus.). 2016; 3(1): 53-55.

[25] Shapovalov SA, Koval VL, Chernaya TA, Pereversev AYu, Derevyanko NA, Ishchenko AA, Mchedlov-Petrossyan NO. Association of indopolycarbocyanine cations with anions of sulfphonephthalein and xanthene dyes. J. Braz. Chem. Soc. $2005 ;$ 16(2): 232-240.

[26] Dewar MJS, Storch DM. Development and use of quantum molecular models. 75. Comparative tests of theoretical procedures for studying chemical reactions. J. Am. Chem. Soc. 1985; 107(13): 3898-3902.

[27] Astakhov SA, Baranov VI, Gribov LA. Theory and methods of computational vibronic spectroscopy. New York: Nova Science Publishers; 2008, $83 \mathrm{P}$.

[28] Stewart JJP. Optimization of parameters for semiempirical methods VI: More modifications to the 
NDDO approximations and re-optimization of parameters. J. Mol. Model. 2013; 19(1): 1-32. http://OpenMOPAC.net (2012). 